\title{
Value Study on the Application of Cross Docking Strategy in Recall Reverse Logistics
}

\author{
Zhihong Zhang \\ Management Department of Langfang Teachers College \\ Langfang,Hebei,China \\ e-mail:zzh2269733@163.com
}

\begin{abstract}
The recall of defective products becomes more and more common in Chinese markets. To make the recall activities more efficient, it is applausible to try new methods of controlling the cost of reverse logistics. Introducing cross docking strategies in the recall reverse logistics has great theoretically applicable potentiality. The present paper, based on the process of cross docking strategies and the logistics segments of the recall, analyzes the economic values and potential risks appearing in the application of the cross docking strategies in the recall reverse logistics. It is proposed that cross docking strategies can satisfy the demands of low costs and speed well in recall logistics and have great applicable value.
\end{abstract}

Keywords—cross docking; recall; reverse logistics; cost control; logistics management

\section{INTRODUCTION}

As accidents caused by defective products in domestic markets happen one after another, the introduction of the recall system of defective products has become extremely urgent. Both the market and the consumers need a complete and healthy recall system to guarantee their interests. However, the implementation of the recall system is not easy with the high cost of reverse logistics as one of the core barriers. The present paper would study how to apply the cross docking strategy in recall process. It is studied that applying the cross docking strategy in recall process would reduce warehousing cost and time wasting, and improve efficiencies and economic benefits. It is hoped that the application of cross docking strategy would provide a feasible reference for the cost control in recall reverse logistics.

\section{DEFINITION AND UNDERSTANDING OF RECALL INVERSE LOGISTICS}

Product recall refers to the process of recalling defective products from the trading markets and end users. Recall reverse logistics refers to the logistics activities to recall defective products. [1]

There is no perfect products. Some defects would threaten consumers' properties and their lives. Thus, the establishment of recall system of defective products is a natural demand of the society. It is an important mechanism to protect consumers' rights and interests. Besides, it is also the reflection of an enterprise's social responsibility. The recall system would reduce the risks of defective products, protect consumers' properties and lives, guarantee the well operation of the market, and promote the development of the enterprise .

The U.S is the earliest country to implement the recall system in the world. Japan, Korea, Canada, U.K. and Australia also have mature recall system. China still does not have complete recall system and the recall mechanism and practices still need to be explored. In recent years, domestic enterprises start to learn the recall system and implement some recalls of defective products. For example, CPSC (Consumer Product Safety Committee) required China to recall children's clothes. AQSIQ (General Administration of Quality Supervision, Inspection and Quarantine of the People's Republic of China) required Sanlu to recall its powdered milk, etc. It is seen that most of the recall practices are passive and domestic enterprises are still not used to the recall system. The reasons for the avoidance and reluctance of recalling defective products can be summarized as: first, worrying that recall would influence their brand image; second, it needs too much logistics cost. In fact, many enterprises, such as $\mathrm{Hp}$, Qiangsheng and Toyota, etc. have practiced many times of recalls and they are not negatively influenced. Instead, they leave an image of 'responsible enterprise' on the consumers and their products are even more trusted. Although the cost of reverse logistics in recall is huge, it can be effectively controlled and reduced by making use of advanced management strategies and technologies. Cross docking strategies popular in the U.S. is one of the effective management models.

\section{CROSS DOCKING STRATEGY AND ITS BASIC PROCESSES}

Cross docking strategy refers to the logistics control realized by crossing the warehouse after receiving the cargo and going directly to the shipping stages. During this process, the least handling and storage work would be done. This would reduce the time from receiving to delivering, reduce the occupation of space for storage and also reduce the cost for stock storage. [2]The cross docking strategy can be traced back to the Agile Strategy based on chain management which were very useful in the timeliness transportation in the U.S. in 1970s . It has unestimated values in reducing space cost and time cost in the process of circulation. 
Traditional cargo flow activities are consisted of five stages: receiving, sorting, storing, handling and transporting. If the management of the five stages are strengthened, the efficiency would be improved and the cost would be reduced to some extent but only limited. If cut down some of the stages under controllable conditions, the logistics cost would be reduced greatly. Based on the above assumptions, the cross stock strategy leap over the storing and sorting stages in the flow of cargo so as to save time cost and space cost in the circulation.

In the 1990s, the cross docking strategy was well known in the world because of its successful operation in the Walmart. After adopting the cross docking strategy, the market share and profit margin of the Wal-mart increase obviously. Later, many enterprises started to adopt and improve the cross docking strategy. Generally speaking, the operation process of cross docking strategy is given as in "Fig. 1 ".

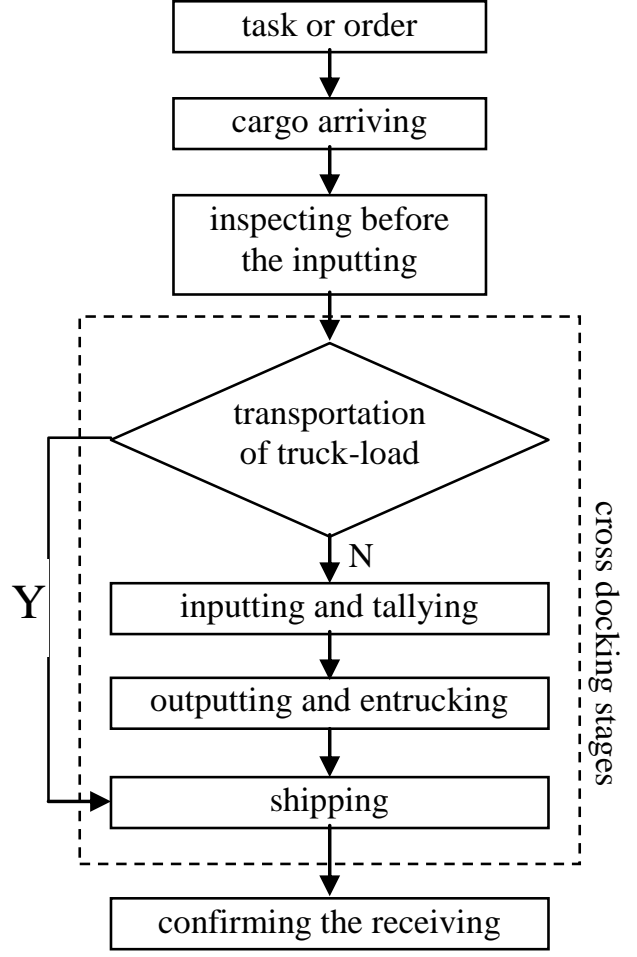

Figure 1. Flow chart of cross docking

The cross docking flow chart shows clearly that the received cargo do not need to go through the stages of warehousing and sorting and can go to the shipping stage directly after being tallied quickly. Compared with traditional warehouse management model, the advantages of cross docking strategy are as follows: low rate of cargo damage and cargo shortage; small number of times of loading and unloading; transportation of truck-load; nearly zero-inventory; short lead time; arriving punctually; small warehouse, etc.[3]

\section{Operation Model of ReCALl REVERSE Logistics BASED ON CROSS DOCKING STRATEGY}

In the research of circulation theories, cross docking strategy is recognized as the mainstream of warehouse management in the future. It accords with modern management concepts, reduce intermediate stages as much as possible and increase the mobility of the products. For those advantages, people start to consider how to apply it in more fields. The present paper tries to learn the feasibility and values of applying the cross docking strategy in the recall of defective products to lower the cost of reverse logistics.

The recall of defective products is a kind of reverse logistics and it is a process from the consumer market to the production filed. How to control the cost of reverse logistics in the recall process is one of the key problems in recall management. "Fig. 2" shows the general operation model formed by the application of cross docking strategy in recall reverse logistics.

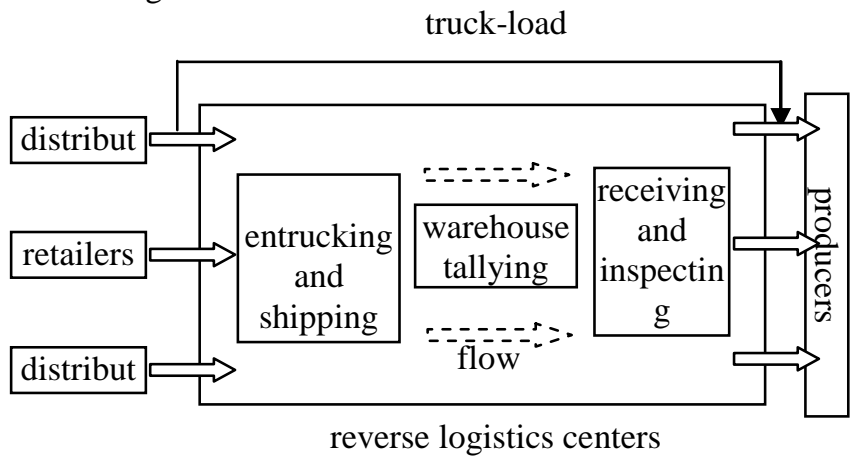

Figure 2. Operation model of recall reverse logistics based on cross docking strategy

Distributors, retailers and consumers are the starting points of recalling defective products. Those defective products would finally go back to original producers, repair centers or destruction centers. The less are the intermediate stages, the less time spent, the better for cost control. In the model shown in chart 2 , the cargo in the reverse logistics centers go through three stages, inspecting when arriving, tallying in the warehouse and loading when outputting. The tallying includes simple sorting, fixing outer packages, pasting necessary labels, etc. Later, the cargo would be stacked on the pallet, in the container or other shipping containers and wait for shipment[4].

Based on the above operation model, the recall reverse logistics process can be described as "Fig 3.". 


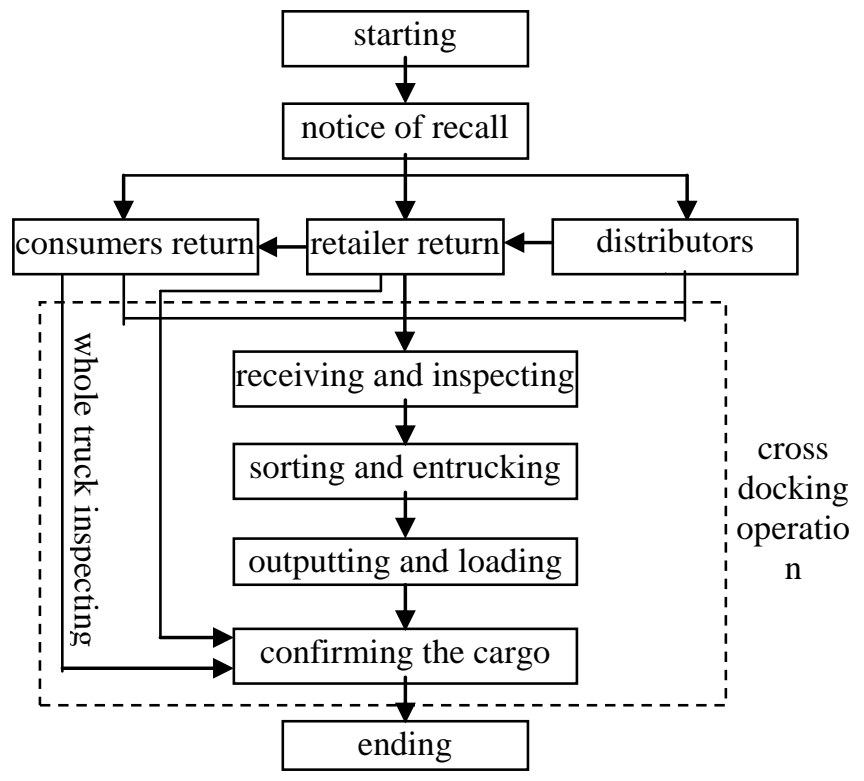

Figure 3. Recall flow chart based on cross docking operation

The successful domestic and foreign recall cases show that valuable recall processes are based on voluntary return of the defective products from the downstream members, which can shorten the recall process and lower the cost. With the introduction of the cross docking strategy in the recall process, the costs can be greatly reduced.

\section{VAlue Study on The APPlication OF Cross DOCKING STRATEGY IN RECALL REVERSE LOGISTICS}

The main reasons for the high cost of reverse logistics in the process of recall are that the recall activities disperse widely, happen abruptly, and have few regularities. Thus, the cost can not be transformed. Solving the above problems are the keys to control the cost of reverse logisitcs in the recall process. The practices in the U.S and Japan have shown that the Agility Logistics is an effective way to solve the problem of high cost. With the Agility Logistics, all members on the supply chain are integrated to a network chain which is unified, quick responded and with a high degree of seamless. The application of agility logistics would greatly reduce time of cargo flow, improve speed and reliability. Based on the Agility Logistics, the cross docking strategy pursues quick response and uninterrupted flow and this would be effective to reduce the cost of logistics in the recall. The recalled products in the recall activities are all the same products with sales package. Thus, the transportation and storage of those products would be simple. Compared with forward logistics, the cross docking strategy can be better used in reverse logistics . the application of cross docking strategy in the recall logistics would be beneficial and can create unestimated economic value.

\section{A. Integrate Dispersed Cargo}

Since the widespread of sales, places and times of the recall disperse. The dispersal becomes the biggest obstacle to the recall and is one of the main reasons for the high cost of the logistics in the recall. The cross docking strategy can integrate the input cargo. Most of the recalled products are the same type for the same enterprise and they are not needed to be sorted according to different types and customers. Assemble the recalled products quickly onto the delivery platform and trucks would reduce the cost of occupying the warehouse as well as time cost.

\section{B. Respond Quickly to Tasks}

Influenced by the dispersal and the long period of the call, the time loss are enormous. The enterprises have to spend a lot of energy and resources to do the work of recall and most of the enterprises claimed that "it is a loss they can not bear to recall" . By leaping over two stages in the warehouse management, the cross docking strategy uses "inputting means outputting" model to manage the inventory. This would waste little time and would response quickly to the tasks of transportation and distribution. In all, the application of cross docking strategy in the recall process would control the time loss efficiently and improve the speed of response.[5]

\section{Reduce the Numbers and Areas of the Warehouses}

The geological range of the recall activity depends on the sales range. Most of the recalls go on the national and even bigger range and warehouses in different areas are needed to store the recalled products. Thus, the enterprises have to spend large number of money for the use of warehouses. The cross docking strategy permits the products to enter the warehouse in different ways and the products can be from different areas. Adopting the "quick inputting and outputting" inventory control model, the recall can be realized without large areas of warehouses. The great saving of warehouses for storing recalled products would improve the turnover ratio and utilization ratio of the warehouses effectively.

\section{Reduce Inventory Cost and Loading Cost}

The dispersal of the recall activity makes the return of defective products can not be unified. In traditional process of return, the early recalledproducts have to be stored for a long time to wait for the concentration of a certain amount of cargos. Besides, dispersed input lead to repeated loading and unloading. The storage cost and loading cost are great. Adopting the cross docking strategy, the storage and tally stages are canceled, "Small and temporary storage" or "zero inventory" are realized. Thus, storage costs can be greatly reduced.

Based on the warehouse management theories, sorting would lead to many times of loading and unloading, which would increase direct costs, cause cargo damages and losses and increase indirect costs. Applying the cross docking strategy, the amount of cargo input in unit time through multi- accesses can increase and the cargo can be output directly with no need of sorting, tallying and packaging, etc.. In this way, the storage time is shortened, the times of loading and unloading are reduced, and the costs of loading and storage are controlled effectively. 


\section{E. Low Damage Rate and Package cost}

Recalled products are the products of the same type that have entered the field of circulation or the field of consumption. All the products have sales package and have no need to be repackaged when they are shipped back to the production enterprises and only simple reinforcement are needed. With no need to be sorted and packaged, the cargo can flow faster and a large sum of expenses in package can be saved. Besides, applying the cross docking strategy in the recall logistics can reduce the loading and unloading activities, and thus the damage rate of the products can be controlled efficiently.

Except for the above advantages, the application of cross docking strategy also can reduce distribution costs, cut down the expenses on social resources and would not interrupt the production, etc. The quick response ability brought by the application of cross docking strategy would create a responsible and efficient market image for the enterprise.

\section{RISK WARNING}

Although the cross docking strategy seems to be simple, the implementation is complicated and proper conditions are needed. The amount of recalled products should achieve a certain degree and there should be extensive circulation network. Plan of product return, coordination of all members and the share of information are all the work to be done. With the enormous values to be expected, the risks are also obvious and should be avoided.

1) No proper preparation would make it difficult to integrate recalled cargo;

2) Bad synchronization of the members would prolong the recall process;

3) No information share would lag the recall;

4) Some products may be stored for a long period if not all products are returned at the same time;
5) All the products would be shipped back to the production enterprise without tallying and sorting.

Those risks can be avoided and solved by proper management strategies. They would no reduce the value of the cross docking strategy and can not be used as a reason for objecting the application of it in recall process. The advantages of applying cross docking strategy in the control of logistics cost can not be denied and deserve practices and wider application.

As a summary, the advantages of cross docking strategy can be best shown in recall activities which become easier in return. The cost of reverse logistics can be efficiently controlled, which make enterprises are more willing to assume their responsibility of recalling defective products. Thus, the system of recalling defective products would be implemented even more smoothly in our country.

\section{ACKNOWLEDGMENT}

2011 Social Science Project Supported by the Foundation for Young Teachers of Langfang Teachers College Project No. LSSQ201101

\section{REFERENCES}

[1] Tang Zhengkang, Products Recall and Reverse Logistics [J], Management Exploration, 2005 (01),pp.26-29.

[2] Ma dongyan, Cross Docking-JIT Strategy in Logistics [J], Logistics Science \&Technology, 2008 (01), pp.01-05.

[3] Ma Dongyan, Studies on the Problems in Cross Docking Operation Control and its Arithmetic [D],Shanghai Jiaotong University (2007),pp.01-09.

[4] Zhangzhihong, Recall of Consumer Electronics and its relation with reverse logistics control [J], Commercial Times, 2011 (01), pp.41-05

[5] Fengwei, Cross Docking-Mainstreams of Warehouse Management in the Future [J], Science and Technology Information, 2008 (31), pp. 167. 